\title{
Evaluación toxicológica comparativa de dos productos farmacéuticos a base de hierro.
}

\section{Artículo Original}

Abril Martínez de los Ríos ${ }^{1}$, Adriana Sandoval ${ }^{1}$, Alejandra Domínguez ${ }^{1}$, Raúl González², Elisa Aznar², Jorge Reyes-Esparza ${ }^{1}$, Lourdes Rodríguez-Fragoso ${ }^{1}$.

${ }^{1}$ Facultad de Farmacia, Universidad Autónoma del Estado de Morelos, Cuernavaca, Morelos, México. ${ }^{2}$ Centro Nacional de Biopreparados, La Habana, Cuba.

\section{RESUMEN.}

Introducción. El hierro es utilizado por la mayoría de las células del organismo ya que juega un papel importante en sus funciones metabólicas. Se sabe que variaciones en la homeostasis del hierro pueden llevar a alteraciones importantes en la salud. El Trofin ${ }^{\circledR}$ y la Ferranina ${ }^{\circledR}$ son dos preparados farmacéuticos a base de hierro que se utilizan para restituir los niveles de hierro en el hombre.

Material y métodos. Se evaluaron y compararon los efectos del Trofin ${ }^{\circledR}$ y la Ferranina ${ }^{\circledR}$ en modelos basados en células y en embriones de pollo.

Resultados. Ferranina ${ }^{\circledR}$ y Trofin ${ }^{\circledR}$ incrementan la viabilidad e inhiben la proliferación de células 293Q, a diferentes concentraciones. Mientras que en las células BMK-16/myc, la Ferranina ${ }^{\circledR}$ incrementó la proliferación celular, en tanto que el Trofin® inhibió la proliferación celular. La Ferranina ${ }^{\circledR}$ modificó el ciclo celular de células BMK-16/myc, disminuyó la población de células en fase G1 y aumentó las células en fase S. El
Trofin ${ }^{\circledR}$ produjo diversas alteraciones en el embrión de pollo. No se observaron alteraciones en los embriones tratados con Ferranina ${ }^{\circledR}$.

Discusión. En esta investigación se muestra que la Ferranina ${ }^{\circledR}$ y el Trofin ${ }^{\circledR}$ producen efectos biológicos diferentes en las células 293Q y BMK-16/myc, así como también en el desarrollo embrionario. Los efectos producidos en los modelos empleados pueden ser debidos a las propiedades farmacéuticas que caracterizan a cada producto. (Rev Biomed 2006; 17:183-194)

Palabras clave: Viabilidad, proliferación y ciclo celular.

\section{SUMMARY.}

Comparative toxicological evaluation of two pharmaceutical products containing iron.

Introduction. Iron is used by most cells in the human body. It plays an important role in all cellular metabolic functions. It is well known

Solicitud de sobretiros: Dra. Lourdes Rodríguez Fragoso, Flavio García \# 32, Colonia Presidentes Ejidales, México, D.F. 04470, México.

Tel.: 56-952-760 Correo electrónico: mlrodrig1@yahoo.com.mx

Recibido el 24/Abril/2006. Aceptado para publicación el 13/Julio/2006.

Este artículo está disponible en http://www.uady.mx/sitios/biomedic/revbiomed/pdf/rb061735.pdf 


\section{A Martínez de los Ríos, A Sandoval, A Domínguez, R González, E Aznar et al.}

that variations in the homeostasis of iron could produce important alterations on health. Trofin ${ }^{\circledR}$ and Ferranina ${ }^{\circledR}$ are two pharmaceutical products containing iron, which are used to restore normal iron levels in the human being.

Material and methods. In this study we evaluated and compared the effects of Trofin ${ }^{\circledR}$ and Ferranina ${ }^{\circledR}$ in in vitro cells and in a chicken embryo model.

Results. Ferranina ${ }^{\circledR}$ and Trofin ${ }^{\circledR}$ increased the viability and inhibited the proliferation of $293 \mathrm{Q}$ cells at different concentrations. Ferranina ${ }^{\circledR}$ increased the cell proliferation of BMK-16/myc cells, whereas Trofin ${ }^{\circledR}$ inhibited cell proliferation. Ferranina ${ }^{\circledR}$ modified the cell cycle of BMK-16/ myc cells. It reduced the cell population in phase G1 and increased the cells in phase S. Trofin ${ }^{\circledR}$ produced several alterations in chicken embryos. No alterations induced by Ferranina ${ }^{\circledR}$ were observed.

Discussion. It was shown that Ferranina ${ }^{\circledR}$ and Trofin ${ }^{\circledR}$ produced different biological effects in 293Q and BMK-16/myc cells, as well as in chick embryo development. The effects produced by both products could be due to the different pharmaceutical properties of each of them.

(Rev Biomed 2006; 17:183-194)

Key words: Viability, proliferation, cell cycle.

\section{INTRODUCCIÓN.}

La anemia por deficiencia de hierro es un problema de salud que afecta a la población mundial (1). Uno de los problemas que conlleva la anemia crónica es la alteración progresiva de algunas funciones celulares metabólicas donde participa este metal, por lo que el impacto sobre la salud llega a ser mucho más grave (2).

El hierro es vital en la formación de la hemoglobina (3). Sin embargo, éste también juega un papel primordial en la función celular, ya que forma parte de los núcleos Fe-S de la cadena respiratoria; asimismo, participa en otras funciones metabólicas celulares. El hierro actúa como cofactor enzimático de la citocromo-oxidasa, el citocromo P450, las peroxidasas, las catalasas, las aldehído oxidasas, etc. (4-8); participa en la síntesis de colágena y elastina $(9,10)$. De ahí que la carencia crónica de hierro pueda afectar el metabolismo del músculo, e inducir alteraciones importantes en los sistemas nervioso central e inmune, el tejido epitelial, y la función tiroidea.

La respuesta al tratamiento de la anemia ferropénica depende de varios factores, entre ellos la causa y gravedad de la deficiencia, la presencia de patologías asociadas, la intolerancia del paciente al hierro y el tipo de forma farmacéutica que se use. Existen numerosas formas farmacéuticas a base de hierro en combinación con otros metales, vitaminas, cofactores, minerales y otros. Sin embargo, la biodisponibilidad y, por tanto, la eficacia y seguridad de estos productos puede variar de un producto a otro (11). Entre los fármacos que se utilizan en la actualidad para el tratamiento de la deficiencia por hierro están: el Trofin ${ }^{\circledR}$ y la Ferranina ${ }^{\circledR}$.

El Trofin ${ }^{\circledR}$, es un producto de origen natural que contiene aminoácidos esenciales, proteínas y minerales, entre ellos, el hierro en forma ferrosa. Este producto farmacéutico, en presentación oral, es utilizado para el tratamiento de la anemia ferropénica ya que aporta hierro de fácil absorción. El Trofin ${ }^{\circledR}$ ha sido utilizado con buenos resultados clínicos en mujeres embarazadas con anemia ferropénica, en niños con problemas de anemia e intolerantes a las sales ferrosas y en pacientes con cáncer en dosis de $0.75 \mathrm{~mL} / \mathrm{kg} /$ día, equivalentes a $180 \mathrm{mg}$ de hierro elemental (12-16). Estudios preclínicos en ratas gestantes han mostrado que el Trofin ${ }^{\circledR}$ a dosis de $20 \mathrm{~mL} / \mathrm{kg}$, una dosis 20 veces mayor que dosis terapéutica, no ejerce efectos teratogénicos (17). La Ferranina ${ }^{\circledR}$, es un complejo sintético, formado por núcleos de hierro férrico cubierto por moléculas de maltosa. Es un producto inyectable y se utiliza como auxiliar en el tratamiento de la anemia ferropénica. Este medicamento es empleado en el último

\section{Revista Biomédica}




\section{Evaluación toxicológica de dos productos con hierro}

trimestre del embarazo y en pacientes adultos con intolerancia al hierro oral, en dosis de $200 \mathrm{mg}$ equivalentes de hierro elemental (18-20).

El hierro es utilizado por la mayoría de las células del organismo ya que es un elemento esencial, pero en concentraciones elevadas es tóxico. El Trofin ${ }^{\circledR}$ y la Ferranina ${ }^{\circledR}$ son medicamentos que a pesar de tener diferencias en cuanto a la forma de ionización del hierro, la forma farmacéutica, la vía de administración, y los efectos secundarios que producen, son utilizados para restituir los niveles de hierro en el hombre. Por lo tanto, es importante conocer qué otros efectos pueden producir a nivel celular y, en particular, en el desarrollo embrionario, puesto que está reportado su uso en pacientes que cursan no sólo con deficiencia de hierro, sino también en aquellos pacientes que requieren regímenes especiales como es la desnutrición, embarazo, o cáncer, por mencionar algunos. Por ello el objetivo de esta investigación fue evaluar comparativamente el efecto de esos productos farmacéuticos a base de hierro sobre la viabilidad, proliferación, ciclo celular y embriogénesis, en modelos in vitro e in vivo.

\section{MATERIAL Y MÉTODOS. Modelo in vitro.}

Se utilizaron células 293Q y BMK-16/myc. Las células 293Q son células epiteliales normales provenientes de riñón fetal humano (CRL-1573 ATCC). Las células BMK-16/myc son células epiteliales de riñón murino que están modificadas genéticamente. Estas células fueron establecidas por una co-transformación en ratones de la cepa BALB/c; contienen la oncoproteína myc y el genoma íntegro del virus del papiloma humano 16 (HPV-16) son tumorigénicas.

\section{Condiciones experimentales.}

Para el tratamiento $1 \times 10^{4}$ células fueron sembradas en placas de 24 pozos, a una confluencia del 50\%. Después de 24 horas, el medio fue desechado y las células fueron lavadas dos veces con PBS (Gibco BRL), e incubadas con los diferentes tratamientos en medio DMEM-F12 (Gibco BRL) complementado con $10 \%$ de suero fetal bovino (Gibco BRL), $4 \mathrm{mM}$ de glutamina (Gibco BRL) y antibióticos (Gibco BRL), a $37^{\circ} \mathrm{C}$, bajo una atmósfera de $5 \% \mathrm{CO}_{2}$ y humedad durante 24 horas.

Las células fueron tratadas con Ferranina ${ }^{\circledR}$ (laboratorio Altana Pharma S.A. de C.V., México; solución inyectable de $100 \mathrm{mg}$ de hierro en $2 \mathrm{~mL}$ ) o Trofin ${ }^{\circledR}$ (Centro Nacional de Biopreparados de la Habana, Cuba; solución oral de 235 mL, equivalente a $630 \mathrm{mg}$ de proteínas y aminoácidos, y $60 \mathrm{mg}$ de hierro ferroso). Las células fueron tratadas con Ferranina ${ }^{\circledR}$ o Trofin ${ }^{\circledR}$ en una dosis equivalente a una concentración de 1, 3, 5 y $7 \mu \mathrm{g} /$ $\mathrm{mL}$ de hierro durante 24 horas. Ambos productos fueron tomados directamente de su presentación farmacéutica, sin ningún procesamiento. Se dejaron células sin tratamiento para utilizarlas como control.

Evaluación del efecto sobre las células.

Ensayos de citotoxicidad, viabilidad y proliferación.

Para los ensayos de citotoxicidad y proliferación celular se utilizó el método de MTT, en el cual se utiliza la sal tetrazólica de bromuro 3-(4,5-dimetiltiazol-2-il)-2,5-difenil tetrazolio (Sigma Chemical Co.). El ensayo se usa como indicador de la función mitocondrial en células vivas, por lo tanto, se puede usar para medir la citotoxicidad, viabilidad y proliferación celular (21). Veinticuatro horas después de la exposición de las células 293Q y BMK-16/myc con Ferranina ${ }^{\circledR}$ o Trofin ${ }^{\circledR}$, se aspiró el medio, se remplazó con $150 \mu \mathrm{L}$ de medio fresco y se adicionó $50 \mu \mathrm{L}$ de una solución de MTT en amortiguador de fosfatos $(5 \mathrm{mg} / \mathrm{mL})$ para tener un volumen final de $200 \mu \mathrm{L}$, y se incubó por 4 horas a $37^{\circ} \mathrm{C}$. Se removió el medio con MTT y posteriormente se agregaron $200 \mu \mathrm{L}$ de dimetilsulfóxido (DMSO, Sigma Chemical Co.) y $25 \mu \mathrm{L}$ de amortiguador

Vol. 17/No. 3/Julio-Septiembre, 2006 


\section{A Martínez de los Ríos, A Sandoval, A Domínguez, R González, E Aznar et al.}

de Soren (glicina $0.1 \mathrm{M}, \mathrm{NaCl} 0.1 \mathrm{M}, \mathrm{pH} 10.5$ ) a cada pozo. La placa se agitó suavemente y se leyó la absorbancia a $550 \mathrm{~nm}$ en un lector de placas (Ultramark, Bio-Rad Co.).

Para los ensayos de proliferación se utilizaron solamente células 293Q. Se siguió el mismo procedimiento utilizado para el ensayo de citotoxicidad, sin embargo, 20 minutos después de exponer las células a los medicamentos se les agregó $2 \mathrm{ng} / \mathrm{mL}$ de factor de crecimiento epidermoide (FCE, Sigma Chemical Co.), para inducir la proliferación celular. Se incluyeron células sin FCE (control) y un grupo de células con FCE solamente. Las células fueron incubadas por 48 horas para permitir la proliferación, siguiendo la metodología ya descrita.

\section{Análisis del ciclo celular.}

El análisis de ciclo celular se realizó mediante citometría de flujo por la técnica de yoduro de propidio (22). Se sembraron $5 \times 10^{4}$ células, tanto 293Q como BMK-16/myc, en placas de 24 pozos en medio DMEM-F12 (Gibco BRL) complementado con $10 \%$ de suero fetal bovino (Gibco BRL), $4 \mathrm{mM}$ glutamina (Gibco BRL) y antibióticos. Células tratadas con Ferranina ${ }^{\circledR}$ o Trofin ${ }^{\circledR}$ y sin ningún tratamiento (control) fueron incubadas por 24 horas. Posteriormente, se obtuvieron las células y fueron fijadas con etanol al $80 \%$ a $4^{\circ} \mathrm{C}$. Las células se centrifugaron a 1500 rpm, se rehidrataron con PBS durante 10 minutos, se centrifugaron nuevamente a $1500 \mathrm{rpm}$, y al paquete celular se le agregó tripsina (30 $\mu \mathrm{g} /$ $\mathrm{mL}$ ) y se incubó a temperatura ambiente durante 10 minutos. Después se le adicionó inhibidor de la tripsina $(277 \mu \mathrm{g} / \mathrm{mL})$ (Sigma Chemical Co.) y se incubó durante 10 minutos a temperatura ambiente; por último, se le adicionó inhibidor de la RNAasa (55 $\mu \mathrm{g} / \mathrm{mL}$ ) (Sigma Chemical Co.) y yoduro de propidio $(150 \mu \mathrm{g} / \mathrm{mL}$ ) (Sigma Chemical Co.). Se incubó a $4^{\circ} \mathrm{C}$ en oscuridad por 15 minutos y, posteriormente, se leyó la fluorescencia en un citómetro de flujo (Becton Dickinson, Mod. Facs Calibur) a $480 \mathrm{~nm}$. El análisis se realizó con el software Cell fit, graficándose el área bajo la curva de la fluorescencia a $585 \mathrm{~nm}$. Se utilizaron células de timo y eritrocitos de pollo como testigo externo.

\section{Modelo de embrión de pollo. Estudio de embriotoxicidad.}

Para los estudios de embriotoxicidad se siguió el procedimiento descrito por Jelinek y col., 1994 (23), en el cual se utilizaron 55 huevos fértiles de pollo (Gallus gallus) sin incubación previa. Estos fueron divididos en cuatro grupos en forma aleatoria: (1) embriones testigo, tratados con solución Ringer; (2) embriones tratados con cafeína (10 mg/mL); (3) embriones tratados con Ferranina ${ }^{\circledR}$ y (4) Trofin ${ }^{\circledR}$ en una dosis equivalente a una concentración de 1, 3, 5 y 7 g/L de hierro.

Los huevos se pesaron, desinfectaron y etiquetaron. Posteriormente se incubaron a una temperatura de $38^{\circ} \mathrm{C}$ con una humedad de $86 \%$ durante 24 horas, para que los embriones alcanzaran el estadio 6 de desarrollo. Transcurrido el tiempo, se procedió a tratar a los huevos bajo condiciones estériles en una campana de flujo laminar. Para ello se extrajo $1 \mathrm{~mL}$ de albúmina a través de un orificio. Una vez tratados los huevos se sellaron e incubaron nuevamente por un periodo de 48 horas, bajo las mismas condiciones de temperatura y humedad, con la finalidad de que los embriones alcanzaran el estadio 18 de desarrollo. Posteriormente, los embriones se extrajeron, fueron fijados (con solución Bouin), teñidos con acetocarmín, se transparentaron con aceite de clavo y se montaron en porta-objetos con resina. Se observaron en un microscopio estereoscópico, se hizo un análisis morfológico comparativo de estructuras del sistema nervioso central, somitas, sistema cardiovascular, ectodermo y endodermo, haciendo énfasis en las estructuras embrionarias que caracterizan al estadio 18 , tanto de los embriones testigo como de aquellos embriones que recibieron los diferentes tratamientos.

\section{Revista Biomédica}




\section{Evaluación toxicológica de dos productos con hierro}

\section{Análisis estadístico.}

Todos los valores fueron expresados como el promedio \pm el error estándar de la media (EEM) de los valores obtenidos en 3 experimentos conducidos por cuadruplicado. El análisis estadístico se hizo utilizando la prueba de Fisher, en donde valores de $\mathrm{p}<0.05$ fueron considerados significativos.

\section{RESULTADOS.}

Efecto de la Ferranina ${ }^{\circledR}$ y Trofin ${ }^{\circledR}$ sobre la viabilidad celular.

Para analizar la viabilidad celular se consideró el total de células testigo viables (sin tratamientos, consideradas como control) como el 100\%. El efecto de la Ferranina ${ }^{\circledR}$ y Trofin ${ }^{\circledR}$ sobre el número de células 293Q viables se puede observar en la figura 1. La Ferranina ${ }^{\circledR}$ incrementó de forma significativa el número de células 293Q viables con las concentración de 1 y $3 \mu \mathrm{g} / \mathrm{mL}$ (18 y 38\%, respectivamente), $\mathrm{p}<0.05$. Mientras que el Trofin ${ }^{\circledR}$ incrementó el número de células $293 \mathrm{Q}$ viables a las concentraciones de 1 , 3 y $5 \mu \mathrm{g} / \mathrm{mL}$, en un 25, 31 y $30 \%$, respectivamente $(\mathrm{p}<0.05)$. Sin embargo, el efecto de ambos medicamentos sobre el número de células BMK-16/myc viables no fue significativo a ninguna de las concentraciones empleadas como

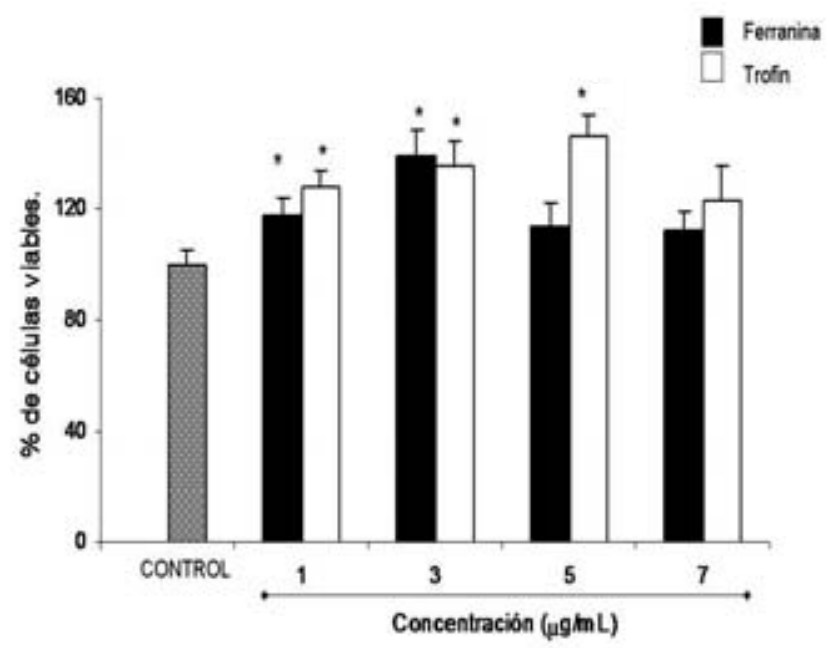

Figura 1.- La Ferranina ${ }^{\circledR}$ y el Trofin ${ }^{\circledR}$ sobre la viabilidad de las células 293Q. Los resultados son expresados como el promedio de tres experimentos realizados por cuadriplicado \pm EEM.

${ }^{*} \mathrm{p}<0.05$ comparado con el control. lo muestra la figura 2. Es importante señalar que aunque el Trofin ${ }^{\circledR}$ no es estéril (es decir, que tiene un límite microbiano), no se observaron problemas de contaminación.

Efecto de la Ferranina ${ }^{\circledR}$ y Trofin ${ }^{\circledR}$ sobre la proliferación celular.

La figura 3 muestra que el tratamiento de las células con $5 \mathrm{ng} / \mathrm{mL}$ de FCE produjo un incremento de la proliferación celular en un $58-65 \%$, a las 48 horas del tratamiento. Al hacer el análisis de la proliferación se encontró que la Ferranina ${ }^{\circledR}$ produjo una inhibición de la proliferación celular del 100\% inducida por el FCE, con las concentraciones de 5 y $7 \mu \mathrm{g} / \mathrm{mL}$ en las células 293Q $(\mathrm{p}<0.05)$; ver figura 3. El Trofin ${ }^{\circledR}$ inhibió la proliferación inducida por el FCE en estas células en $100 \%$ con las concentraciones de 1 y $3 \mu \mathrm{g} / \mathrm{mL}$, y en un $60 \%$ con las concentraciones de 5 y $7 \mu \mathrm{g} / \mathrm{mL}(\mathrm{p}<0.05)$. En la figura 4 se observa el efecto de los medicamentos sobre la proliferación inducida por el FCE en las células BMK-16/myc. Se observó que la Ferranina ${ }^{\circledR}$ incrementó la proliferación celular con todas las concentraciones utilizadas ( 2.5 a 2.9 veces, $\mathrm{p}<0.05$ ); en tanto que

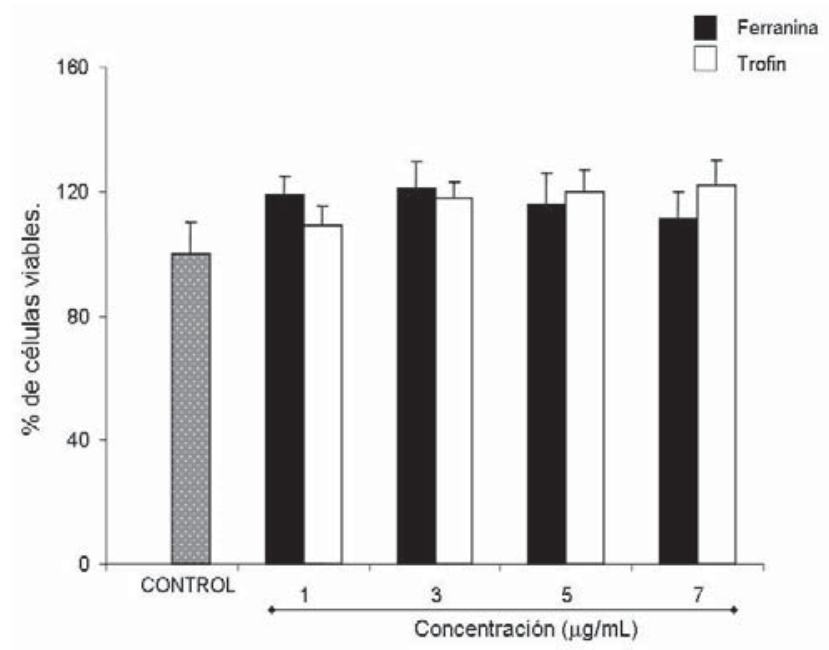

Figura 2.- Efecto de la Ferranina ${ }^{\circledR}$ y el Trofin ${ }^{\circledR}$ sobre la viabilidad de las células BMK-16/myc. No se observaron incrementos significativos sobre la viabilidad con los dos medicamentos a las dosis evaluadas, aunque siempre fueron ligeramente superiores al control.

Vol. 17/No. 3/Julio-Septiembre, 2006 
A Martínez de los Ríos, A Sandoval, A Domínguez, R González, E Aznar et al.

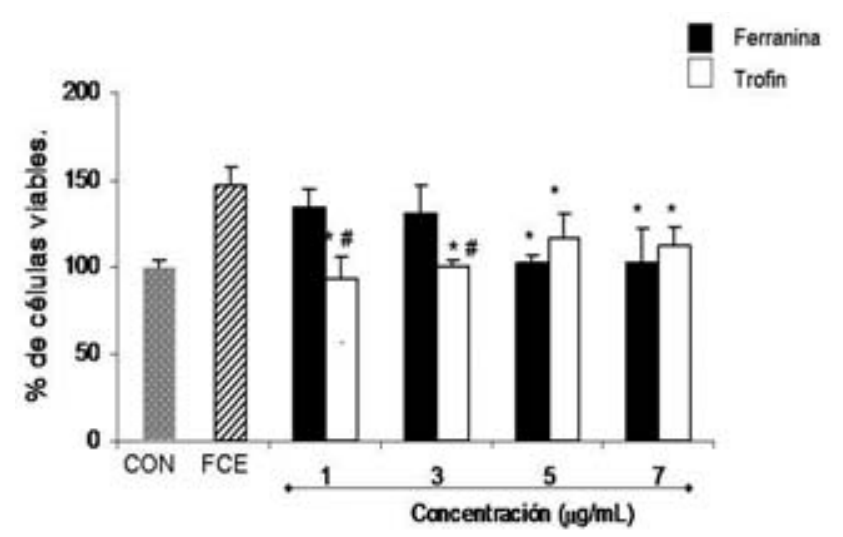

Figura 3.- Efecto de la Ferranina ${ }^{\circledR}$ y el Trofin ${ }^{\circledR}$ sobre la proliferación de las células 293Q. Los resultados son expresados como el promedio de tres experimentos realizados por cuadriplicado \pm EEM.

$* \mathrm{p}<0.05$ comparado con el control.

\# $\mathrm{p}<0.05$ comparado con el grupo de FCE.

el Trofin® inhibió la proliferación celular en un $100 \%$ con todas las concentraciones $(\mathrm{p}<0.05)$.

Efecto de la Ferranina ${ }^{\circledR}$ y Trofin ${ }^{\circledR}$ sobre el ciclo celular.

En la figura 5 se puede observar el efecto que produjo la Ferranina ${ }^{\circledR}$ sobre el ciclo celular de las células BMK-16/myc. Este producto redujo la población de células en la fase G1 del ciclo celular con todas las concentraciones empleadas (2537\%), p $<0.05$ Asimismo, incrementó la población de células en la fase $S$ del ciclo celular (100 a $120 \%)$ con todas las concentraciones, $(p<0.05)$. En la figura 6 se observa que el Trofin ${ }^{\circledR}$ también redujo la población de células BMK-16/myc en fase G1 con las concentraciones 1 , 3 y $5 \mu \mathrm{g} / \mathrm{mL}$ (31-37\%), $\mathrm{p}<0.05$; mientras que la población de células en fase $S$ aumentó en un 100-120\% con las concentraciones 1 , 3 y $5 \mu \mathrm{g} / \mathrm{mL}, \mathrm{p}<0.05$.

Efecto de la Ferranina ${ }^{\circledR}$ y Trofin ${ }^{\circledR}$ sobre la embriogénesis.

Como testigo positivo se utilizó cafeína (10 mg/mL), la cual se sabe que es teratogénica y que produce una gran variedad de defectos en el desarrollo embrionario. En el cuadro 1 se observa que la Ferranina ${ }^{\circledR}$ no produjo

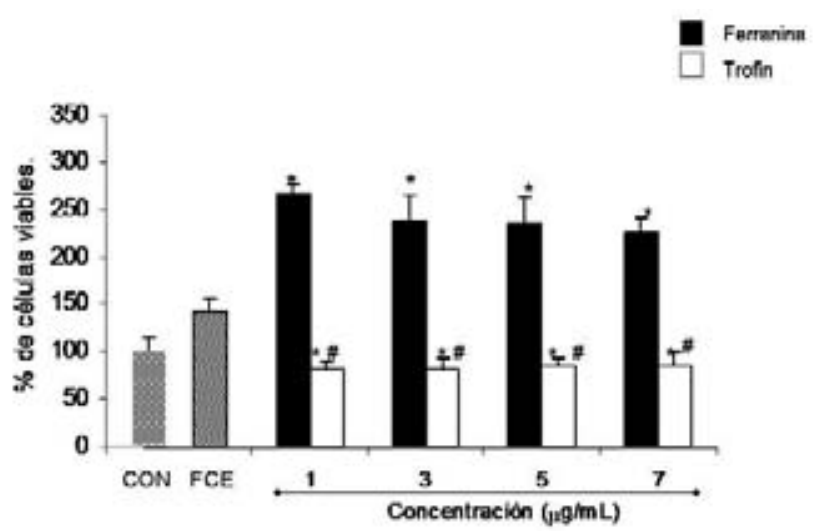

Figura 4.- Efecto de la Ferranina ${ }^{\circledR}$ y el Trofin ${ }^{\circledR}$ sobre la proliferación de las células BMK-16/myc. Los resultados son expresados como el promedio de tres experimentos realizados por cuadriplicado \pm EEM.

* $\mathrm{p}<0.05$ comparado con el control.

\# $\mathrm{p}<0.05$ comparado con el grupo de FCE.

alteraciones en el desarrollo embrionario, ni en los aparatos y sistemas estudiados, a ninguna de las concentraciones estudiadas. Por el contrario, se observa que el Trofin ${ }^{\circledR}$ produjo alteraciones a todas las concentraciones estudiadas. En el sistema nervioso central produjo alteraciones con 5 y $7 \mu \mathrm{g} / \mathrm{mL}$, en el 20 y $30 \%$ de los embriones, respectivamente. En el aparato cardiovascular y en somitas produjo alteraciones a todas las concentraciones estudiadas en una forma dosis dependiente. En placodas ópticas, placodas óticas y en endodermo produjo alteraciones sólo a altas concentraciones, 5 y $7 \mu \mathrm{g} / \mathrm{mL}, 20$ y $40 \%$ respectivamente. En la figura 7 se pueden observar algunas de las alteraciones que produjo el Trofin ${ }^{\circledR}$ durante el desarrollo embrionario de pollo.

\section{DISCUSIÓN.}

La célula capta el hierro vía un proceso de endocitosis dependiente de un receptor transferrina-transferrina. El hierro que entra a la célula es utilizado para funciones biológicas esenciales incluyendo el transporte de oxígeno, transferencia de electrones, y síntesis de ácido desoxirribonucléico, sin embargo, se sabe que el exceso de hierro está asociado con algunos

\section{Revista Biomédica}




\section{Evaluación toxicológica de dos productos con hierro}
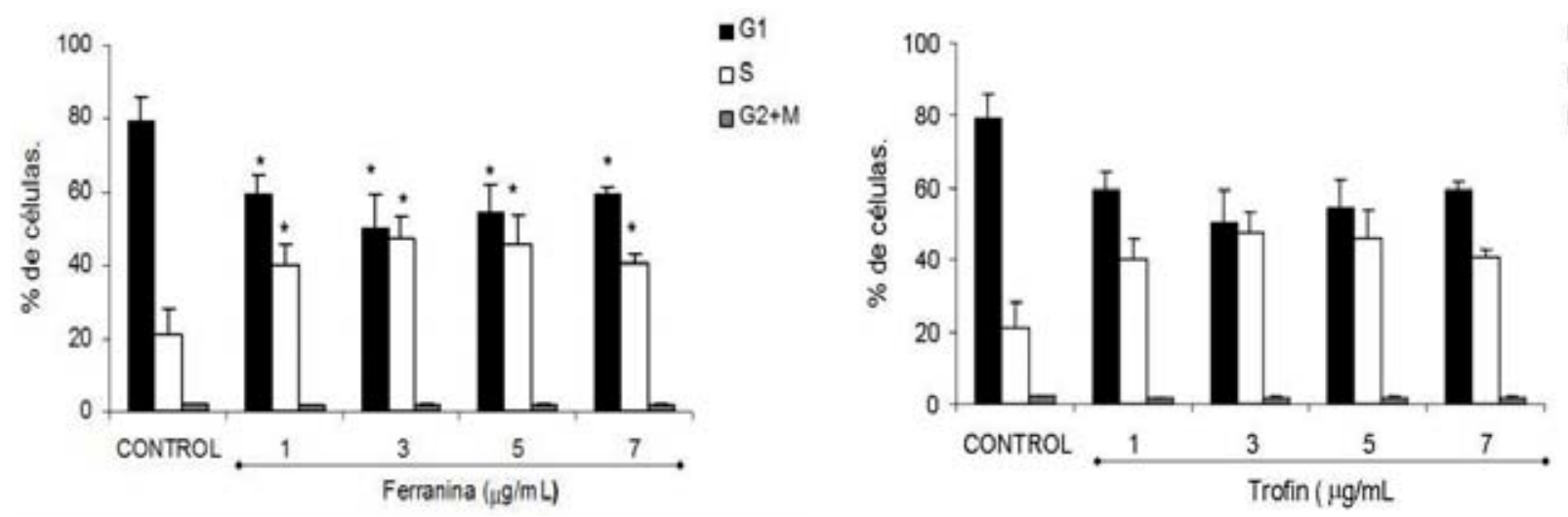

Figura 5.- Efecto de la Ferranina ${ }^{\circledR}$ sobre el ciclo celular de las células BMK-16/myc. Los resultados son expresados como el promedio de tres experimentos realizados por cuadriplicado \pm EEM.

$* \mathrm{p}<0.05$ comparado con el control.

procesos patológicos (24-25).

En esta investigación se muestra que la Ferranina ${ }^{\circledR}$ y Trofin ${ }^{\circledR}$ producen efectos biológicos diferentes en las células 293Q y BMK-16/myc, así como también en el desarrollo embrionario. Los efectos producidos en los modelos empleados pueden ser debidos a las propiedades farmacéuticas que caracterizan a cada producto. La Ferranina ${ }^{\circledR}$ tiene como principio activo el hierro férrico $\left(\mathrm{Fe}^{+3}\right)$, forma química que le permite unirse a la

Figura 6.- Efecto del Trofin ${ }^{\circledR}$ sobre el ciclo celular de las células BMK-16/myc. Los resultados son expresados como el promedio de tres experimentos realizados por cuadriplicado \pm EEM.

transferrina para transportarse y, por lo tanto, es utilizable por las células $(26,27)$. En el Trofin $®$, el hierro no sólo es ferroso $\left(\mathrm{Fe}^{+2}\right)$, sino que contiene aminoácidos, proteínas, azúcares provenientes de la miel de abeja y propóleos. Este medicamento es absorbido por células especializadas como los enterocitos, de ahí que su vía de administración sea oral (28). Todos estos son elementos que sugieren que los mecanismos de acción en los modelos escogidos de embrión de pollo e in vitro son diferentes para ambos medicamentos y también

\section{Cuadro 1}

Tipo de alteraciones producidas por la Ferranina ${ }^{\circledR}(\mathrm{F})$ y Trofin ${ }^{\circledR}(\mathrm{T})$ sobre el desarrollo embrionario del pollo.

\begin{tabular}{|c|c|c|c|c|c|c|c|c|c|}
\hline \multirow{2}{*}{$\begin{array}{l}\text { Tipo de } \\
\text { alteración }\end{array}$} & \multirow{2}{*}{$\begin{array}{c}\text { Cafeina } \\
10 \mathrm{mg} / \mathrm{ml}\end{array}$} & \multicolumn{2}{|c|}{$1 \mu \mathrm{g} / \mathrm{mL}$} & \multicolumn{2}{|c|}{$3 \mu \mathrm{g} / \mathrm{mL}$} & \multicolumn{2}{|c|}{$5 \mu \mathrm{g} / \mathrm{mL}$} & \multicolumn{2}{|c|}{$7 \mu \mathrm{g} / \mathrm{mL}$} \\
\hline & & F & $\mathrm{T}$ & F & $T$ & F & $\mathrm{T}$ & F & $T$ \\
\hline $\begin{array}{l}\text { Desarrollo } \\
\text { embrionario }\end{array}$ & $100 \%$ & $\cdots$ & $100 \%$ & $\ldots$ & $100 \%$ & $\cdots$ & $100 \%$ & $\cdots$ & $100 \%$ \\
\hline $\begin{array}{r}\text { Sistema } \\
\text { nervioso }\end{array}$ & $30 \%$ & $\cdots$ & $\cdots$ & $\cdots$ & -.. & $\cdots$ & $20 \%$ & $\cdots$ & $40 \%$ \\
\hline $\begin{array}{c}\text { Sistema } \\
\text { cardiovascular }\end{array}$ & $70 \%$ & $\cdots$ & $20 \%$ & $\cdots$ & $40 \%$ & $\cdots$ & $40 \%$ & $\cdots$ & $70 \%$ \\
\hline Somitas & $62 \%$ & $\cdots$ & $20 \%$ & $\cdots$ & $20 \%$ & $\cdots$ & $40 \%$ & $\cdots$ & $70 \%$ \\
\hline $\begin{array}{l}\text { Placodas } \\
\text { ópticas }\end{array}$ & $68 \%$ & $\cdots$ & $\cdots$ & $\cdots$ & $\cdots$ & $\cdots$ & $20 \%$ & $\cdots$ & $40 \%$ \\
\hline $\begin{array}{c}\text { Placodas } \\
\text { óticas }\end{array}$ & $35 \%$ & $\cdots$ & $\cdots$ & $\cdots$ & $\cdots$ & $\cdots$ & $20 \%$ & $\cdots$ & $40 \%$ \\
\hline Ectodermo & $25 \%$ & $\cdots$ & $\cdots$ & $\cdots$ & $\cdots$ & $\cdots$ & $20 \%$ & $\cdots$ & $40 \%$ \\
\hline
\end{tabular}


A Martínez de los Ríos, A Sandoval, A Domínguez, R González, E Aznar et al.

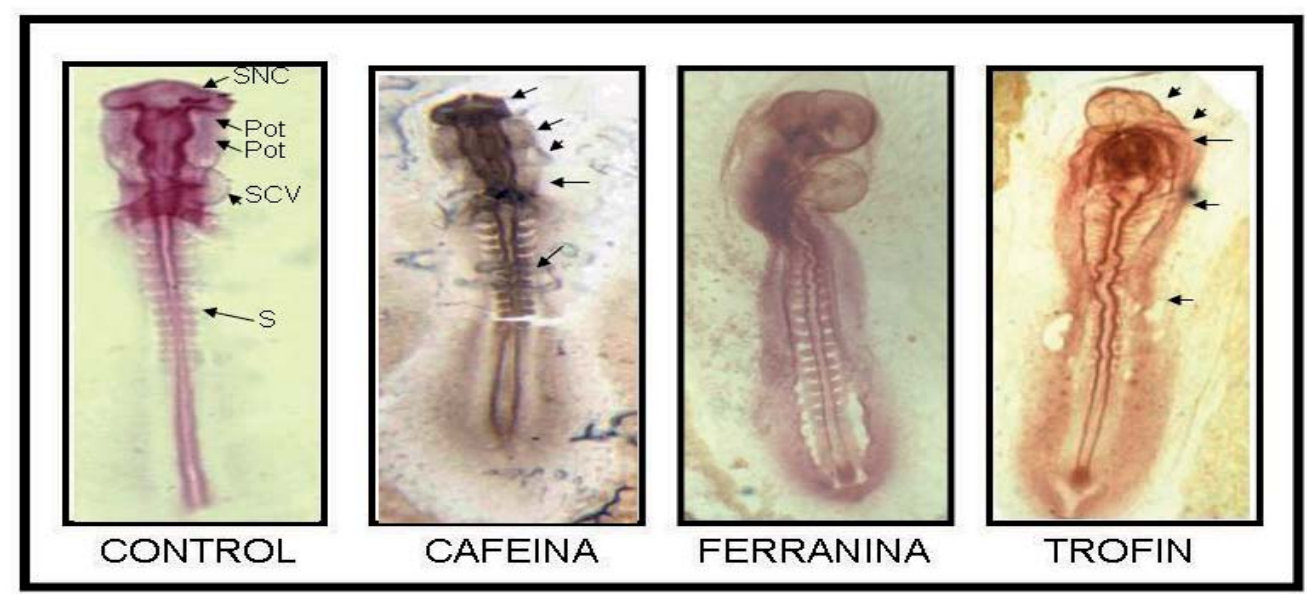

Figura 7.- Efecto de la Ferranina ${ }^{\circledR}$ y Trofin ${ }^{\circledR}$ sobre el desarrollo embrionario del pollo. En el embrión control y el tratado con la Ferranina ${ }^{\circledR}$ no son apreciables cambios morfológicos, mientras que en los tratados con cafeína y Trofin ${ }^{\circledR}$ se observan modificaciones embrionarias en sistema nervioso (SNC), sistema cardiovascular (SCV), placodas ópticas (Pop), placodas óticas (Pot) y somitas (S). Las alteraciones son indicadas con flechas.

contribuyen a explicar los resultados obtenidos.

La citotoxicidad por hierro ha sido previamente documentada. Rauen y cols., 2004, han mostrado que el hierro per se puede inducir daño celular y apoptosis en hepatocitos en cultivo, vía una transición en la permeabilidad mitocondrial (29). Por otro lado, se sabe que el hierro es esencial para la función neuronal, pero que en exceso genera neurodegeneración $(30,31)$. Se sabe que concentraciones elevadas de hierro reactivo pueden incrementar la vulnerabilidad neuronal al estrés oxidativo y, que la acumulación de hierro puede incrementar los efectos de toxinas endógenas y ambientales $(32,33)$. Los resultados muestran que tanto la Ferranina ${ }^{\circledR}$ como el Trofin $₫$ no produjeron toxicidad en las células estudiadas. Por el contrario, en las células 293Q ambos medicamentos incrementaron el número de células viables. Mientras que en las células BMK-16/myc no indujeron cambios en el número de células. Esto indica que el hierro no fue tóxico en las células epiteliales renales a las concentraciones utilizadas, y que los constituyentes presentes en la formulación del Trofin ${ }^{\circledR}$, no son tóxicos para éstas.

El hierro es indispensable para la síntesis de ácido desoxirribonucléico (ADN). Se sabe que la carencia de hierro detiene la proliferación, presuntamente porque el metal se requiere para la actividad de la ribonucleótido reductasa y otras enzimas involucradas en la división celular (34). El papel central del hierro en la proliferación celular ha sido demostrado por agentes quelantes que pueden atravesar la membrana plasmática, unirse al metal dentro de la célula y limitar su biodisponibilidad. Los agentes como la desferrioxamina inhiben el crecimiento de una variedad de células tumorales en cultivo y reducen en forma importante la proliferación de linfocitos T, como consecuencia de la depleción de hierro (35). Los resultados mostraron que el Trofin® inhibió la proliferación de ambas líneas celulares. Por el contrario, la Ferranina ${ }^{\circledR}$ inhibió la proliferación de las células 293Q e incrementó la proliferación de las células BMK-16/myc. Hay evidencias que señalan que el hierro está involucrado en la inducción y/o progresión de varios tumores humanos y de tumores inducidos experimentalmente en animales (36). Por ejemplo, ha sido previamente mostrado que el hierro de la dieta incrementa la velocidad y el número de tumores en la carcinogénesis cutánea y de colon inducidos en ratones. Se ha propuesto que el hierro puede inducir actividad co-carcinogénica por estimular la proliferación celular; por otra parte, se sabe que el hierro participa en la generación de

\section{Revista Biomédica}




\section{Evaluación toxicológica de dos productos con hierro}

radicales hidroxilo, por lo que la sobrecarga de hierro puede generar un estrés oxidativo, el cual puede jugar un papel importante en la progresión de la carcinogénesis en células previamente dañadas o transformadas (37-39). Por tal razón, no es raro que la Ferranina ${ }^{\circledR}$ haya incrementado la proliferación de las células BMK-16/myc, ya que estas células están modificadas genéticamente, contienen el genoma íntegro del virus del papiloma humano y expresan la oncoproteína myc, además de ser tumorigénicas.

La proliferación celular es altamente controlada en tejidos normales y es aberrante durante la progresión de la enfermedad, como la tumorigénesis. Entre los moduladores del ciclo celular hay nutrientes específicos, los cuales funcionan como fuentes de energía o regulan la producción y/o función de proteínas necesarias para que las células avancen a través de un ciclo replicativo (40). La enzima ribonucleótido reductasa participa en la conversión de ribonucleótidos en desoxirribonucleótidos, y juega un papel esencial en la síntesis de ADN, contiene un centro con dos átomos de $\mathrm{Fe}^{3+}$. Esta enzima ha sido asociada con la transformación y progresión maligna (41).

Al hacer el análisis del ciclo celular de las células BMK-16/myc, se observó que la Ferranina ${ }^{\circledR}$ redujo la fase G1 y aumentó la fase $\mathrm{S}$ del ciclo celular. Estos resultados, muestran un efecto marcado del hierro férrico contenido en la Ferranina ${ }^{\circledR}$ sobre estas células. La mayor disponibilidad del $\mathrm{Fe}^{+3}$ para la enzima puede incrementar su actividad y ser un factor para que un mayor número de células inicien el ciclo celular. Se debe recordar que algunos quelantes de $\mathrm{Fe}^{+3}$ se han utilizado como antineoplásicos (42). Estos resultados pueden constituir un elemento desfavorable para la Ferranina ${ }^{\circledR}$ en cuanto a su limitado uso en pacientes con enfermedades malignas. Por el contrario, el tratamiento de las células con Trofin ${ }^{\circledR}$ no modificó el ciclo celular. Esto podría explicarse por el hecho de que el $\mathrm{Fe}^{+2}$ no es utilizable por la ribonucleótido reductasa y, por tanto, no modifica la proliferación celular, esto permite que el Trofin ${ }^{\circledR}$ sea un medicamento seguro en pacientes oncológicos.

En este trabajo se realizó un estudio de embriotoxicidad utilizando para ello el modelo de embrión de pollo para evaluar el potencial teratogénico de la Ferranina ${ }^{\circledR}$ y el Trofin ${ }^{\circledR}$. Se sabe que en la etapa embrionaria, las células están en constante duplicación para la formación de tejidos, órganos y estructuras importantes para el desarrollo, como el eje neural que guiará al sistema nervioso central y cardiovascular, entre otros. Los requerimientos de hierro en el desarrollo embrionario han sido señalados previamente y está bien documentado el papel que el hierro juega en el desarrollo embrionario $(43,44)$; asimismo, ha sido señalado que puede ser tóxico si el embrión se expone a concentraciones elevadas (45). Los resultados muestran que la Ferranina ${ }^{\circledR}$ no produjo alteraciones en el desarrollo del embrión de pollo. Sin embargo, el Trofin ${ }^{\circledR}$ produjo un retardo en el desarrollo embrionario con todas las concentraciones estudiadas. El efecto observado podría ser atribuido no sólo a la presencia de hierro en el Trofin ${ }^{\circledR}$, sino también a la presencia de ingredientes inactivos, cuya biodisponibilidad en humanos es desconocida.

La teratogenicidad del Trofin ${ }^{\circledR}$ ya fue previamente evaluada en un modelo murino (13), el cual demostró que no produjo efectos tóxicos en las ratas gestantes, en los embriones ni en los fetos, es decir, no produjo efectos teratogénicos. Los hallazgos que se encontraron en este modelo pueden estar relacionados con la presencia de hierro férrico que entra en contacto directo con el embrión, a diferencia de la Ferranina ${ }^{\circledR}$ que, como ya se dijo, está en estado ferroso, o la presencia de sustancias en la formulación del Trofin ${ }^{\circledR}$ que resultan tóxicas para el embrión. Se debe considerar que el embrión de pollo está programado para nutrirse de los componentes de la ovoalbúmina y la yema, incluso después de la eclosión. Sin embargo, es un sistema biológico sensible, el cual puede ser afectado por los pirógenos u otros componentes del 


\section{A Martínez de los Ríos, A Sandoval, A Domínguez, R González, E Aznar et al.}

medicamento. La ausencia de efectos teratógénicos en ratas gestantes, reportada previamente para este medicamento, podría indicar que la barrera digestiva no permite su completa absorción, o su paso a través de la barrera placentaria, ello podría explicar que los embriones provenientes de madres gestantes que lo consumen por vía oral no presenten alteración alguna.

El presente trabajo pone en evidencia la diferencia de efectos que pueden observarse tras la administración de la formulación de Ferranina ${ }^{\circledR}$ y Trofin ${ }^{\circledR}$. Además, sugiere la posibilidad de que el hierro férrico, forma química que le permite unirse a la transferrina para su transportación, pueda llegar a ser contraproducente en pacientes oncológicos, por lo que debe ser utilizado con precaución. Estos razonamientos sugieren el posible efecto beneficioso que se pudiera obtener de un preparado no inyectable a base de hierro hemo. Es importante realizar más estudios de teratogenicidad en otros modelos para descartar posibles efectos tóxicos.

\section{AGRADECIMIENTOS.}

Los autores agradecen a la Dra. Sophie Hallez (Universidad de Bruselas, Bélgica) y al Dr. Vicente Madrid por la donación de las células.

\section{REFERENCIAS.}

1.- Freire N. La anemia por deficiencia de hierro. Estrategias de la OPS-OMS para combatirla. Rev Salud Pública Mex 1998; 40:199-205.

2.- Lipschitz DA. Iron deficiency anemia. The anemia of chronic disease. Sideroblastic anemia and iron overload. En Stein JH, Internal Medicine. $4^{\text {th }}$ ed. St Louis: Mosby Year Book, 1994:835-45.

3.- Hentze MW, Muckenthaler MU, Andrews NC. Balancing acts: molecular control of mammalian iron metabolism. Cell 2004; 117: 285-97.

4.- Yu Y, Radisky E, Leibold EA. The iron-responsive element binding protein. Purification, regulation and clonation in rat liver. J Biol Chem 1992; 267:1905-10.

5.- Rouault TA, Tong WH. Iron-sulphur cluster biogenesis Revista Biomédica and mitochondrial iron homeostasis. Nat Rev Mol Cell Biol 2005; 6:345-51.

6.- Napier I, Ponka P, Richardson DR. Iron trafficking in the mitochondrion: novel pathways revealed by disease. Blood 2005; 105:1867-74.

7.- Zhang AS, Sheftel AD, Ponka P. Intracellular kinetics of iron in reticulocytes: evidence for endosome involvement in iron targeting to mitochondria. Blood 2005; 105:368-75.

8.- Koc M, Nad'ova Z, Truksa J, Ehrlichova M, Kovar J. Iron deprivation induces apoptosis via mitochondrial changes related to Bax translocation. Apoptosis 2005; 10:381-93.

9.- Gardi C, Arezzini B, Fortino V, Comporti M. Effect of free iron on collagen synthesis, cell proliferation and MMP-2 expression in rat hepatic stellate cells. Biochem Pharmacol 2002; 64:1139-45.

10.- Bunda S, Kaviani N, Hinek A. Fluctuations of intracellular iron modulate elastin production. J Biol Chem 2005; 21; 280:2341-51.

11.- Uzel C, Conrad ME. Absortion of heme iron. Semin Hematol 1998; 35:27-34.

12.- Fernánde-Delgado N, Gautier Du Defaix H, Forrelat Barrios M, Cedré Hernandez T, González Hernández R y Aznar García E. Tratamiento con trofin en niños intolerantes a sales de hierro. Rev Cubana Hematol Inmunol Hemoter 2000; 16:115-21.

13.- Aznar E, González R, Barquié M, González M, Díaz Y. Prevención de la deficiencia de hierro en embarazadas suplementadas con productos de origen natural Neotrofin (Tabletas) y TrofinVital (Líquido oral). Rev Cubana Farmacia 2001; Suplemento Especial. 35:269-73.

14.- López-Carballosa A, Reboso J, Portuondo R, Díaz E. Efecto del uso del trofin sobre el estado de nutrición de hierro en niños desnutridos menores de dos años con anemia ferripriva. Rev Esp Nutr Comunitaria 2004; 10:56-63.

15.- Aznar E, González R, Carrasco M, Leyva B. Y Muñoz B. Aplicación del Trofin en Geriatría. Rev Mexicana Ciencias Farmacéuticas 1997; 28:20-7.

16.- Aznar E, González R, Barroso E, Catalá M. Valor nutricional del suplemento proteico mineral Trofìn en pacientes con cáncer. Revista Cubana de Farmacia 2002, Suplemento Especial; 35:267-9 


\section{Evaluación toxicológica de dos productos con hierro}

17.- Alvarez SA, Gutiérrez MA, Valenzuela BC, Aznar E. Evaluación de la actividad teratogénica del Trofin, un antianémico de origen natural. Rev Mexicana Ciencias Farmacéuticas 1999; 30:19-23.

18.- Nielsen P, gabbe EE, Fischer R, Heinrich HC. Bioavailability of iron from oral ferric polymaltose in humans. Arzneimittelforschung 1994, 44:743-8.

19.- Borbolla JR, Cicerro RE, Dibildox M, Sotress D., Gutiérrez R. Complejo polimaltosado férrico vs. sulfato ferroso en el tratamiento de la anemia por deficiencia de hierro en lactantes. Rev Mex Ped 2000; 67:63-7.

20.- Jacobs P, Wood L, Bird AR. Erythrocytes: better tolerance of iron polymaltose complex compared with ferrous sulfhate in the treatment of anemia. Hematol 2000; 5:77-83.

21.- Virág L, Kerékgyártó C, Fachet J. A simple, rapid and sensitive fluorimetric assay from the measurement of cell-mediated cytotoxicity. J Immunol Meth 1995; 185: 199-208.

22.- Méndez-Herrera MC, Támez L, Candido A, ReyesEsparza J, Pedernera E. Follicle stimulating hormone increases somatic and germ cell number in the ovary during chick embryo development. General and Comparative Endocrinology 1998; 111:207-15.

23.- Jelinek R, Marhan O. Validation of the chick embryotoxicity screening test (CHEST). A comparative study. Funct Dev Morphol 1994; 4:317-23.

24.- Cazzola M, Bergamaschi G. Manipulations of cellular iron metabolism for modulating normal and malignant cell proliferation: achievements and prospects. Blood 1990; 75: 1903-8.

25.- Taketani S. Acquisition, mobilization and utilization of cellular iron and heme: endless finding and growing evidence of tigh regulation. Tohoku J Exp Med 2005; 205: 297-318.

26.- Xiong S, She H, Takeuchi H, Han B, Engelhardt JF, Barton CH, Zandi E, Giulivi C, Tsukamoto H. Signaling role of intracellular iron in NF-kappa B activation. J Biol Chem 2003; 278:17646-54.

27.- Jacobs P, Wornald L, Gregory M. Absortion of iron polymaltose and ferrous sulphate in rats and human. S Afr Med J 1979; 15:1065-70.
28.- Kaltwasse JP. Bioabilitiy and therapeutic efficassy of bivalent and trivalent iron preparations. Arneim Forsch Drug Res 1987; 37:122-7.

29.- Rauen U, Petrat F, Sustmann R, De Groot H. Ironinduced mitochondrial permeability transition in cultured hepatocytes. J Hepatol 2004; 40:607-15.

30.- Liang LP, Patel M. Iron-sulfur enzyme mediated mitochondrial superoxide toxicity in experimental Parkinson's disease. J Neurochem 2004; 90:1076-84.

31.- Zecca L, Youdim MB, Riederer P, Connor JR, Crichton RR. Iron, brain and neurodegenerative disorders. Nat Rev Neurosci 2004; 5: 863-73.

32.- Kress GJ, Dineley KE, Reynolds IJ. The relationship betwwen intracellular free iron and cell injury in cultured neurons, astrocytes and oligodendrocytes. J Neurosci 2002; 22:5848-55.

33.- Reddel RR, Hedley DW, Sutherland RL. Cell cycle effects of iron depletion on T-47D human breast cancer cells. Exp Cell Res 1985; 161:277-83.

34.- Bierer BE, NathanDG. The effect of desferrithiocin, an oral iron chelator, on T cell function. Blood 1990; 76: 2052-9.

35.- Cazzola M. Bergamaschi G. manipulations of cellular iron metabolism for modulating normal a malignant cell proliferation: achievements and prospects. Blood 1990; 75:1903-8.

36.- Simonart T, Degraef C, Stordeur P, Noel JC, Mossellmans R, Van Vooren JP, Parent D, Boelaert JR, Heenen M, Galand P. Iron induces bcl-2 expression in human dermal microvascular endothelial cells. Free Radical Res 2001; 34:221-9.

37.- Siegers CP, Baumann D, Baretton G, Younes M. Dietary iron enhances the tumor rate in dimethylhydrazine-induced colon carcinogenesis in mice. Cancer Lett 1998; 41:251-6.

38.- Bhasin G, Kauser H, Athar M. Low iron state is associated with reduced tumor promotion in a two stage mouse skin carcinogenesis model. Food Chem Toxicol 2002; 40:1105-11.

39.- Le NT, Richardson DR. The role of iron in cell cycle progression and the proliferation of neoplastic cells. Biochim Biophys Acta 2002; 2:1603:31-46. 


\section{A Martínez de los Ríos, A Sandoval, A Domínguez, R González, E Aznar et al.}

40.- Thelander M, Gräslund A, and Thelander L. Subunit M2 of mammalian ribonucleotide reductase. Characterization of a homogeneous protein isolated from M2-overproducing mouse cells. J Bio Chem 1985; 260:2737-47.

41.- Wyllie S, Liehr JG. Enhancement of estrogeninduced renal tumorigenesis in hamster by dietary iron. Carcinogenesis 1998; 19:1285-90.

42.- Lebropoulou EP, Datsis A, Kekelos S, Rogdakis A, Katsiki E, Labropoilou CM, Spiliotis J, Christopoulou A. The presence and significance of iron in neoplasia of colorectum. Tech Coloproctol 2004; 8:s211-3.

43.- Nasr-Esfani M, Johnson MH, Aitken RJ. The effect of iron and iron chelators on the in vitro block to development of the mouse pre-implantation embryo: BAT6 a new medium for improved cultured of mouse embryos in vitro. Hum Reprod 1990; 5:997-1003.

44.- Morath DJ, Mayer-Proschel M. Iron deficiency during embryogenesis and consequences for oligodendrocyte generation in vivo. Dev Meurosci 2002; 24:197-207.

45.- Gilani SH, Alibhai Y. Teratogenicity of metals to chick embryos. J Toxicol Environ Health 1990; 30: 23-31.

\section{Revista Biomédica}

